Article

\title{
Control Strategy for Active Hierarchical Equalization Circuits of Series Battery Packs
}

\author{
Xiaogang $\mathrm{Wu}{ }^{1,2}{ }^{1}$, Zhihao Cui ${ }^{1}$, Xuefeng $\mathrm{Li}^{1}{ }^{1}$, Jiuyu $\mathrm{Du}^{2, *}$ and Ye Liu ${ }^{1}$ \\ 1 School of Electrical and Electronic Engineering, Harbin University of Science and Technology, Harbin 150080, \\ China; xgwu@hrbust.edu.cn (X.W.); cuizh_ma18@hrbust.edu.cn (Z.C.); \\ lixuefeng_ma16@hrbust.edu.cn (X.L.); liuye_ma17@hrbust.edu.cn (Y.L.) \\ 2 State Key Laboratory of Automotive Safety and Energy, Tsinghua University, Beijing 100084, China \\ * Correspondence: dujiuyu@tsinghua.edu.cn
}

Received: 5 April 2019; Accepted: 28 May 2019; Published: 30 May 2019

\begin{abstract}
Most series battery active equalization circuits implement the equalization first within the series and then between the series, which restricts the equilibrium speed. A hierarchical equalization circuit topology based on the Buck-Boost module is applied in this paper. The equalization is divided into two different equalization processes according to the equilibrium energy flow. The two equalization processes can be performed simultaneously, and the currents in the different hierarchical circuits do not affect each other, thus achieving simultaneous equalizations within the series and between the series. An equalization condition of the terminal voltage is applied and simulations and experiments on charge, discharge, and static equalizations in the four series-connected ternary lithium-ion batteries are performed.
\end{abstract}

Keywords: series battery packs; active hierarchical equalization; control strategy

\section{Introduction}

Lithium-ion batteries have been widely used in electric vehicle energy storage systems owing to their high energy density, no memory effect, and long cycle life [1]. The lithium-ion battery is characterized by low voltage, which makes it necessary to use a multi-cell battery in series to achieve high-voltage output in order to meet the voltage requirements of the electric drive system of the electric vehicle [2]. However, in an energy storage system in which the multi-cell battery is connected in series, the battery may overcharge and over-discharge during the charging and discharging processes of the series power battery pack owing to the inconsistency of the cells. This can shorten the life of the battery pack, in addition to presenting a safety hazard. Therefore, it is necessary to regulate the energy of the batteries in the energy storage system through an equalization circuit to ensure that all batteries are equalized in voltage and capacity [3,4].

The equalization circuit topology can be divided into resistance equalization, capacitance equalization, inductance equalization, LC (inductance and capacitance) equalization, and transformer equalization circuits according to the different energy storage components [5,6]. Among them, resistance equalization is a form of energy equalization, and the rest are non-energy equalizations. Capacitance equalization $[7,8]$ uses a capacitor for energy transfer. It is designed to achieve energy equalization through the voltage difference between the cells. However, the small voltage difference between the cells makes it difficult to achieve an equalization of the energy transfer. Inductance equalization $[9,10]$ uses the inductance for the energy transfer; the equalization current is easy to control, but the performance of the equalizer is determined by the circuit structure of the equalizer and the equalization strategy. LC equalization [11-13] realizes capacitance equalization through an LC oscillation circuit, which compensates the shortcoming of the small voltage difference in capacitance 
equalization. However, it has high switching frequency and low equalization efficiency, and requires complex control of the equalization circuit. Transformer equalization [14-16] mostly uses a flyback transformer for energy transfer. The equalizer has a large volume, and the equalization efficiency and equalization speed are limited.

In the research on equilibrium control strategy, reference [17] presented a linear optimization model, which involved an equilibrium strategy based on energy loss and equilibrium time, and proposed a model predictive control method to cope with the frequent changes in the working state. Reference [18] proposed an equalization technique based on the remaining available energy of the battery pack to improve the energy utilization efficiency. Reference [19] proposed a new equalization strategy, which combined the battery pack charging and single charging modes to construct an equalization algorithm. Reference [20] proposed two model predictive control strategies for simultaneously solving the equalization and charging problems. Reference [21] aimed to build an adaptive quasi-sliding mode observer designed for single cell state of charge (SOC) estimation. A discrete time quasi-sliding mode-based strategy utilizing the saturated equalization current was proposed, which enabled the converters to operate together effectively to achieve single SOC equalization. A variable domain fuzzy controller was proposed in [22] to adaptively maintain the equalized current between the cells in a series battery pack under different conditions. In [23], the battery equalization and voltage/current regulation subsystems were combined to significantly lower the overall system complexity, and the current of each battery was self-regulated according to its terminal voltage. Reference [24] used a proportional integral control strategy to achieve SOC equalization of the battery. Reference [25] proposed a novel inductor-based layered bidirectional equalizer. This equalizer was composed of two layers of balancing circuits connected in parallel. Each layer contains multiple balancing sub-circuits based on buck-boost converters. These balancing sub-circuits can equalize the corresponding cells simultaneously, and allow the dynamic adjustment of the equalization path and equalization threshold.

In summary, the existing equilibrium topology circuits generally have problems such as slower equalization speed, poor controllability of the equalization energy, and unsatisfactory equalization effect. Although several researches have been performed on equalization control algorithm and adequate equalization effect has been achieved, it often fails to meet the requirements for the equilibrium speed in engineering applications. To this end, this paper implements a converter-based equalization method for active equalization. Based on the buck-boost active stratified equalization circuit, a control strategy for simultaneous equalizations within and between the packs is proposed, which realizes the charging, discharging, and static operations of the battery pack. The energy equalizations in the three states are set to achieve continuous and controllable energy of the series battery pack, thereby accelerating the equilibrium speed of the battery pack.

\section{Active Equalization Circuit Topology and Working Principle}

\subsection{Topology}

The equalization circuit designed in this paper is shown in Figure 1. Figure 1a shows the battery equalization structure diagram and Figure $1 b$ shows the schematic of the equalization module. The entire equalization circuit comprises two adjacent cells and an equalization module, which form the first-layer equalization group. Two adjacent first-layer equalization groups along with the equalization module constitute the second-layer equalization group. Two adjacent second-layer equalization groups along with the equalization module form a third-layer equalization group, and so on. Thus, the battery is divided into several layers according to the total number of serial sections of the battery. The battery equalization module consists of two MOSFETs (Metal-Oxide-Semiconductor Field-Effect Transistor) and one energy storage inductor, as shown in Figure $1 \mathrm{~b}$. 


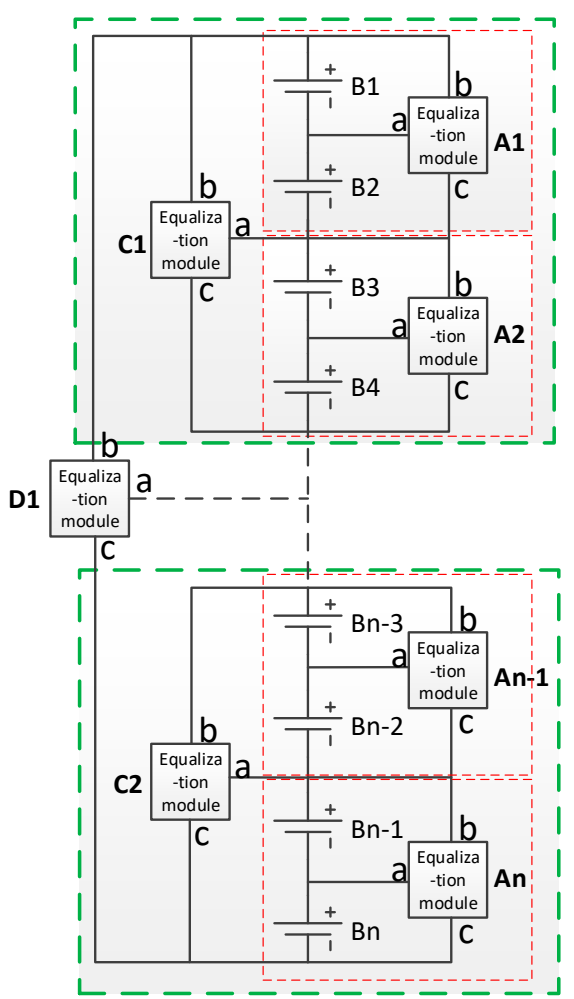

(a)

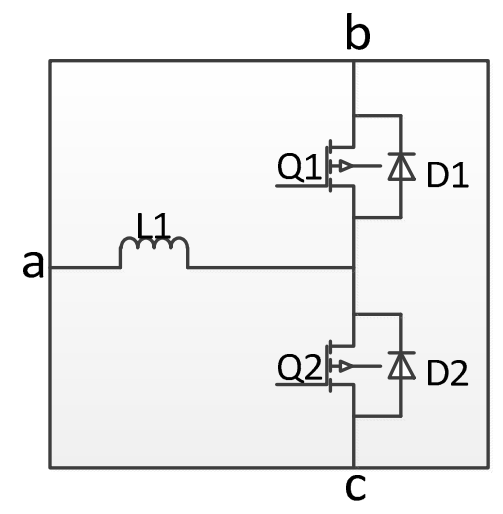

(b)

Figure 1. Battery equalization circuit topology: (a) Battery equalization structure diagram; (b) Schematic of the equalization module.

Assume that the number of series connections of the batteries is $n$ knots. If $n$ is odd, the last battery is used as the first-level equalization group; if $n$ is even, each two-cell battery is used as the first-level equalization group. The number of equalization modules used in the equalization circuit mentioned in this paper is $n-1$, that is, the number of MOSFET is $2 n-2$ and the number of inductors is $n-1$. This arrangement can achieve equalization between the batteries over a wide range, shorten the equilibrium path, and speed up the equalization time.

\subsection{Working Principle of the Equalization Circuit}

This paper takes four batteries as an example to describe the principle of active equalization of the circuit. The structure of the equalization circuit is shown in Figure 2.

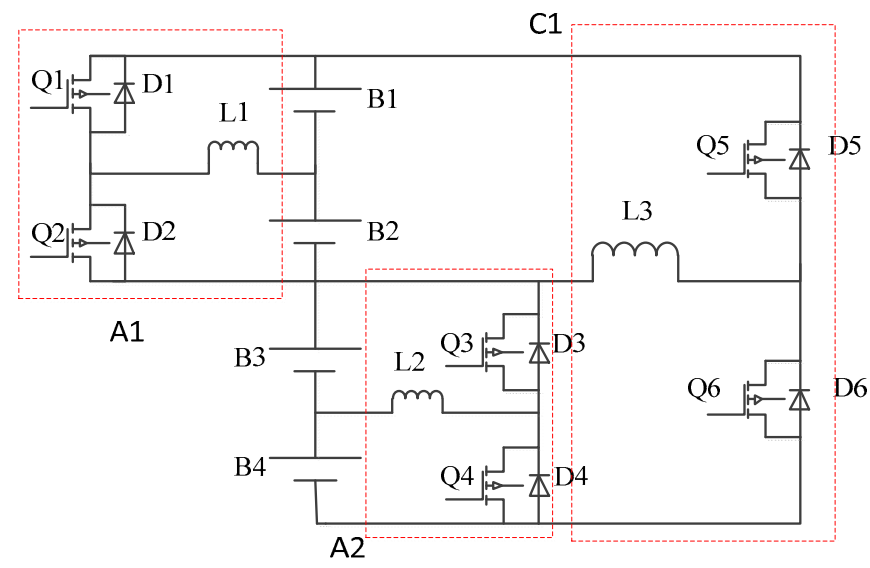

Figure 2. Battery pack equalization circuit. 
The equalization process of the battery pack in the stationary state is simpler than that in the charging and discharging states, and the equalization process in the charging and discharging states includes the equalization process in the static state. Therefore, the emphasis is on the equalization process in the charging and discharging states.

\subsubsection{Equalization Process during Battery Pack Charging}

When the battery pack is charged, it is assumed that the voltage of the battery cell B1 is higher than the voltage of the battery cell B2 and the average voltage of B1 and B2 is greater than the average voltage of B3 and B4. The equilibrium threshold is reached when

$$
\left\{\begin{array}{c}
V_{\mathrm{B} 1}-V_{\mathrm{B} 2}>V_{T} \\
\frac{V_{\mathrm{B} 1}+V_{\mathrm{B} 2}}{2}-\frac{V_{\mathrm{B} 3}+V_{\mathrm{B} 4}}{2}>V_{T}
\end{array},\right.
$$

where $V_{T}$ is the equilibrium threshold voltage. $V_{T}$ is taken as $0.025 \mathrm{~V}$ in this paper.

At this time, the equalization circuit performs the equalization. The switching period of the circuit is denoted by $T$, the duty ratio is denoted by $\mathrm{D}$, and the running time is denoted by $\mathrm{t}$. The equalization is mainly divided into the following two stages:

(1) The first stage: $0<\mathrm{t}<\mathrm{DT}$, as shown in Figure 3.

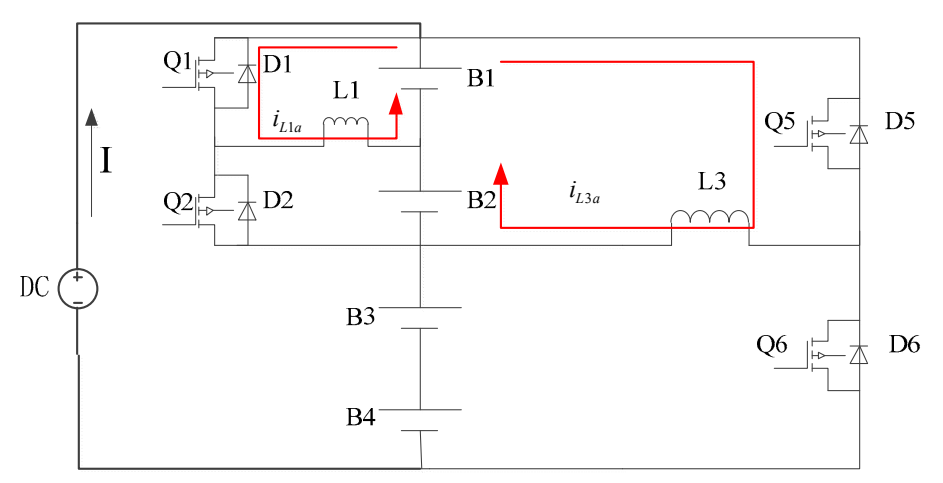

Figure 3. Schematic of first stage of charge equalization.

As can be seen from Figure 3, at this time, the MOSFET Q1 is turned on, and the battery B1, the MOSFET Q1, and the inductor L1 form a loop, which is the equalization group of the first layer. Battery $\mathrm{B} 1$ charges the inductor $\mathrm{L} 1$. The charge is cut off when $\mathrm{t}=\mathrm{DT}$, and the inductor L1 current reaches the maximum. At the same time, the MOSFET Q5 is turned on. The batteries B1 and B2, MOSFET Q5, and inductor L3 form a loop, which is the equalization group of the second layer. The batteries B1 and $\mathrm{B} 2$ charge the inductor L3. When $\mathrm{t}=\mathrm{DT}$, the charge is turned off, and the current in the inductor L3 reaches the maximum.

At this stage, the charging currents flowing through the batteries B1 and B2 are respectively expressed as

$$
\begin{gathered}
i_{\mathrm{B} 1 \mathrm{a}}=I-i_{\mathrm{L} 1 \mathrm{a}}-i_{\mathrm{L} 3 \mathrm{a}}, \\
i_{\mathrm{B} 2 \mathrm{a}}=I-i_{\mathrm{L} 3 \mathrm{a}} .
\end{gathered}
$$

In the above formulae, $I$ is the charging current of the power source, $i_{\mathrm{B} 1 \mathrm{a}}$ is the current flowing through the battery $\mathrm{B} 1, i_{\mathrm{B} 2 \mathrm{a}}$ is the current flowing through the battery $\mathrm{B} 2, i_{\mathrm{L} 1 \mathrm{a}}$ is the current flowing through the inductor L1, and $i_{\mathrm{L} 3 \mathrm{a}}$ is the current flowing through the inductor L3.

(2) The second stage: DT $<\mathrm{t}<T$, as shown in Figure 4. 


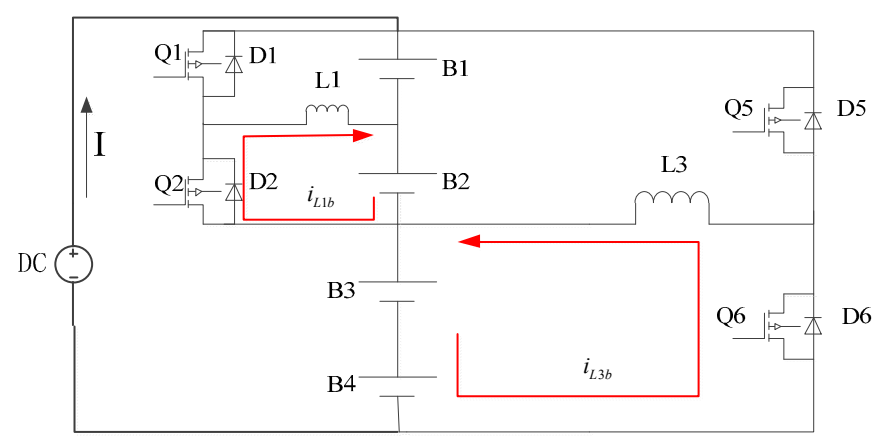

Figure 4. Schematic of the second stage of charge equalization.

At this time, the diode D2 performs freewheeling, and the battery B2, the diode D2, and the inductor L1 form an energy storage circuit, which is the equalization group of the first layer. The inductor L1 discharges into the battery B2 until the current drop in the inductor L1 is zero; while the diode D6 performs freewheeling, the batteries B3 and B4, the diode D6, and the inductor L3 form an energy storage circuit, which is the equalization group of the second layer. The inductor L3 discharges into the batteries B3 and B4 until its current drops to zero.

At this stage, the charging currents flowing through batteries B2 and B3 are respectively expressed as

$$
\begin{aligned}
& i_{\mathrm{B} 2 \mathrm{~b}}=I+i_{\mathrm{L} 1 \mathrm{~b}}, \\
& i_{\mathrm{B} 3 \mathrm{a}}=I+i_{\mathrm{L} 3 \mathrm{~b}} .
\end{aligned}
$$

In the above formulae, $I$ is the charging current of the power source, $i_{\mathrm{B} 2 \mathrm{~b}}$ is the current flowing through the battery $\mathrm{B} 2, i_{\mathrm{B} 3 \mathrm{a}}$ is the current flowing through the battery $\mathrm{B} 3, i_{\mathrm{L} 1 \mathrm{~b}}$ is the current discharged by the inductor L1, and $i_{\mathrm{L} 3 \mathrm{~b}}$ is the current discharged by the inductor L3.

\subsubsection{Equalization Process during Battery Pack Discharge}

When the battery pack is discharged, it is assumed that the voltage of the battery cell B4 is lower than that of the battery cell B3, and the average voltage of B3 and B4 is smaller than the average voltage of $\mathrm{B} 1$ and B2. The equilibrium threshold is reached when

$$
\left\{\begin{array}{c}
V_{\mathrm{B} 3}-V_{\mathrm{B} 4}>V_{T} \\
\frac{V_{\mathrm{B} 1}+V_{\mathrm{B} 2}}{2}-\frac{V_{\mathrm{B} 3}+V_{\mathrm{B} 4}}{2}>V_{T}
\end{array} .\right.
$$

At this time, the equalization circuit performs the equalization. The switching period of the circuit is denoted by $T$, the duty ratio is denoted by $\mathrm{D}$, and the running time is denoted by $t$. The equalization is mainly divided into the following two stages:

(1) The first stage: $0<\mathrm{t}<\mathrm{DT}$, as shown in Figure 5.

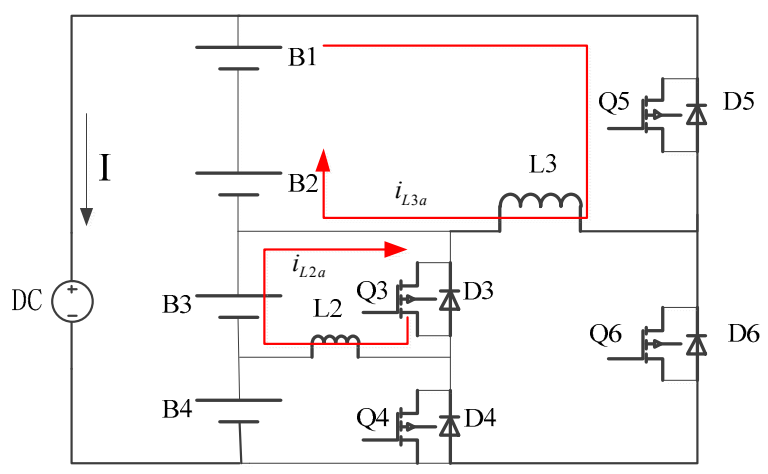

Figure 5. Schematic of the first stage of discharge equalization. 
As can be seen from Figure 5, at this time, the MOSFET Q3 is turned on, and the battery B3, the MOSFET Q3, and the inductor L2 form a loop, which is the equalization group of the first layer. The battery B3 charges the inductor L2. When $\mathrm{t}=\mathrm{DT}$, the charge is cut off and the current in the inductor $\mathrm{L} 2$ reaches the maximum. At the same time, the MOSFET Q5 is turned on. The batteries B1 and B2, MOSFET Q5, and inductor L3 form a loop, which is the equalization group of the second layer. The batteries B1 and B2 charge the inductor L3. When $\mathrm{t}=\mathrm{DT}$, the charge is turned off, and the inductor L3 current reaches the maximum.

At this stage, the discharge currents flowing through batteries B2 and B3 are respectively expressed as

$$
\begin{aligned}
& i_{\mathrm{B} 2 \mathrm{a}}=I+i_{\mathrm{L} 3 \mathrm{a}}, \\
& i_{\mathrm{B} 3 \mathrm{a}}=I+i_{\mathrm{L} 2 \mathrm{a}},
\end{aligned}
$$

where $I$ is the discharge current of the power supply, $i_{\mathrm{B} 2 \mathrm{a}}$ is the current flowing through the battery B2 during discharge, $i_{\mathrm{B} 3 \mathrm{a}}$ is the current flowing through the battery $\mathrm{B} 3, i_{\mathrm{L} 3 \mathrm{a}}$ is the current flowing through the inductor $\mathrm{L} 3$, and $i_{\mathrm{L} 2 \mathrm{a}}$ is the current flowing through the inductor $\mathrm{L} 2$.

(2) The second stage: DT $<\mathrm{t}<\mathrm{T}$, as shown in Figure 6.

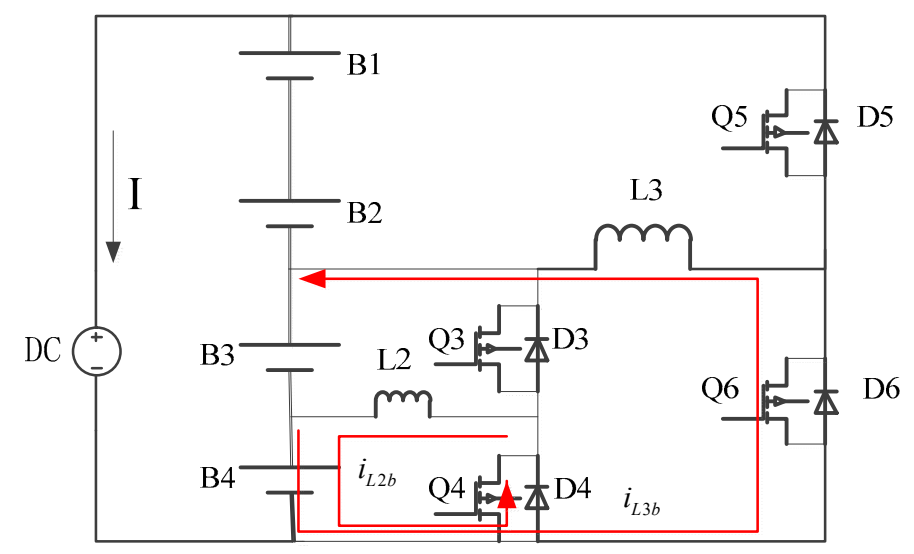

Figure 6. Schematic of the second stage of discharge equalization.

At this time, the diode D4 performs the freewheeling, and the battery B4, the diode D4, and the inductor L2 form an energy storage circuit, which is the equalization group of the first layer. The inductor L2 discharges into the battery B4 until the current of the inductor L2 drops to zero; while the diode D6 is turned on, the batteries B3 and B4, the diode D6, and the inductor L3 form an energy storage circuit, which is the equalization group of the second layer. The inductor L3 discharges into the batteries B3 and B4 until its current drops to zero.

At this stage, the discharge currents flowing through the cells B3 and B4 are respectively expressed as

$$
\begin{gathered}
i_{\mathrm{B} 3 \mathrm{~b}}=I-i_{\mathrm{L} 3 \mathrm{~b}}, \\
i_{\mathrm{B} 4 \mathrm{a}}=I-i_{\mathrm{L} 2 \mathrm{~b}}-i_{\mathrm{L} 3 \mathrm{~b}} .
\end{gathered}
$$

In the formula, $I$ is the discharge current of the power source, $i_{\mathrm{B} 3 \mathrm{~b}}$ is the current flowing through the battery $\mathrm{B} 3$ during discharge, $i_{\mathrm{B} 4 \mathrm{a}}$ is the current flowing through the battery $\mathrm{B} 4, i_{\mathrm{L} 3 \mathrm{~b}}$ is the current discharged by the inductor $\mathrm{L} 3$, and $i_{\mathrm{L} 2 \mathrm{~b}}$ is the current discharged by the inductor $\mathrm{L} 2$.

\section{Simultaneous Equilibrium Control Strategy between Groups within Groups}

In order to realize the fast equalization of the series battery pack, a control strategy for simultaneous equalizations within and between groups is proposed based on the active stratified equalization circuit and voltage as the equilibrium condition. 
The control strategy mainly adopts the adjacent average differential pressure method, whereby the equalization at threshold is set between every two cells as well as between two adjacent equalization groups in each layer.

When the number of series connected cells is even, that is, $n$ is even, the working condition for the adjacent equalization groups in each layer is

$$
|| \frac{V_{1}+V_{2}+\cdots+V_{k}}{k}|-| \frac{V_{k+1}+V_{k+2}+\cdots+V_{n}}{k} \|>V_{T}
$$

When the number of series connected cells is odd, that is, $n$ is an odd number, the working condition of the adjacent equalization groups in each layer is

$$
\left|\frac{V_{1}+V_{2}+\cdots+V_{k}}{k}\right|-\mid \frac{V_{k+1}+V_{k+2}+\cdots+V_{n}}{k-1} \|>V_{T}
$$

When the equalization group of each layer reaches the equilibrium threshold, the corresponding equalization module is turned on to perform battery equalization. In this paper, the voltage threshold $V_{T}$ is considered as $0.025 \mathrm{~V}$.

The proposed hierarchical equalization control strategy is shown in Figure 7.

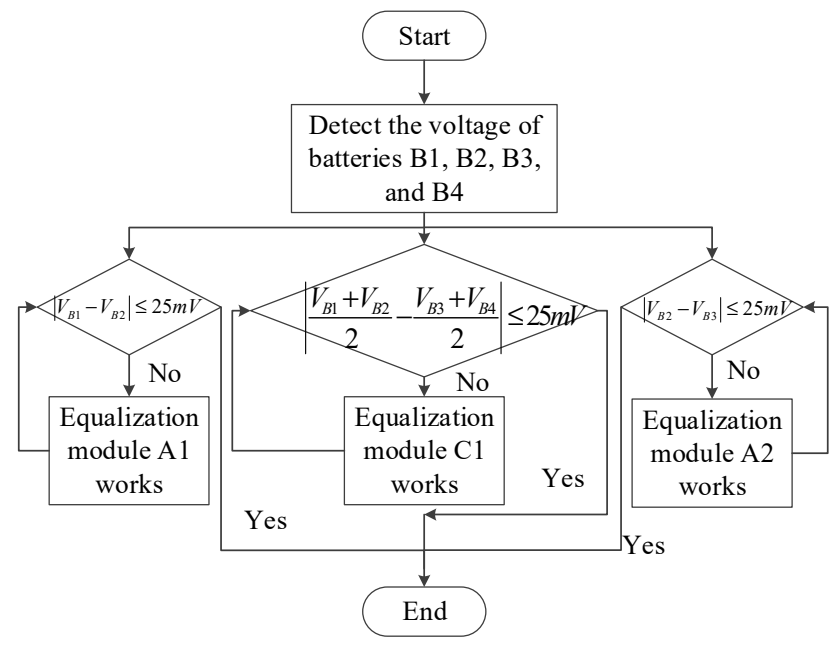

Figure 7. Layered equalization control strategy.

Figure 7 shows an example of the control strategy employed for a series battery pack composed of four power batteries. Using the control strategy of simultaneous equalizations within and between groups within the groups, the voltage of the four batteries is first detected and the threshold value is judged as follows: (1) if $V_{\mathrm{B} 2}-V_{\mathrm{B} 1} \geq V_{T}$, the equalization module A1 is turned on; if not, A1 does not operate. (2) If $V_{\mathrm{B} 4}-V_{\mathrm{B} 3} \geq V_{T}$, the equalization module $\mathrm{A} 2$ is enabled; if not, A2 does not operate. (3) If $\left(V_{\mathrm{C} 1}-V_{\mathrm{C} 2}\right) / 2 \geq V_{T}$, the equalization module $\mathrm{A} 3$ is turned on; if not, $\mathrm{A} 3$ does not operate. The above three conditions are judged at the same time. When any one reaches the open condition, the corresponding equalization module is turned on.

During the operation of the equalization module, the current in the group and the inter-group current are controlled by a pulse width modulator (PWM); the selected PWM wave frequency is $10 \mathrm{kHz}$. In order to ensure that all the energy can be released during the equalization process to prevent the inductor from saturating, the duty ratio needs to be set to $\mathrm{D} \leq 0.5$. Here, the duty ratio was set to 0.45 . 


\section{Analysis of Simulation and Experimental Results}

\subsection{Parameter-Based Calculation of Equalization Circuit}

Taking the equalization of single batteries B1 and B2 as an example, the process of equalization was analyzed (the voltage of B1 is greater than that of B2). The current waveform is shown in Figure 8. Here, $V_{\text {gs }}$ is the drive signal of the MOSFET, $I_{\mathrm{L}}$ is the current flowing through the inductor, Ip is the maximum value of the current flowing through the inductor, $I_{1}$ is the current flowing through MOSFET $\mathrm{Q} 1$, and $I_{2}$ is the current flowing through free-wheeling diode D2. When MOSFET Q1 is turned on, $I_{\mathrm{L} 1}$ flows through inductor L1. When the switching frequency is high, $I_{\mathrm{L} 1}$ rises approximately linearly, while inductor L1 is charged to store energy.

$$
I_{\mathrm{L} 1}=\frac{V_{\mathrm{B} 1} \mathrm{t}}{\mathrm{L}}(0<\mathrm{t}<\mathrm{DT})
$$

Here, $V_{\mathrm{B} 1}$ is the voltage of battery $\mathrm{B} 1, \mathrm{~L}$ is the value of the inductor, $\mathrm{t}$ is the switch-on time of the MOSFET, $\mathrm{D}$ is the duty ratio of the switch, and $T$ is the period of the switch.

$I_{\mathrm{L} 1}$ reaches its maximum value Ip at DT, at which point MOSFET Q1 is turned off. The energy stored in the inductor freewheels through diode D2 and the current drops approximately linearly to zero.

$$
I_{p}=\frac{V_{\mathrm{B} 1} \mathrm{DT}}{\mathrm{L}}
$$

Therefore, the average value of the current flowing through the battery B1 in one switching cycle is:

$$
I_{1 \mathrm{~d}}=\frac{I_{p} \mathrm{DT}}{2} \frac{1}{T}
$$

The average value of the current flowing through the battery B2 in one switching cycle is:

$$
I_{1 \mathrm{c}}=\frac{I_{p} T_{f}}{2} \frac{1}{T}
$$

Here, $T_{f}$ is the time required for the current flowing through the inductor to drop from its peak to zero.

To completely release the energy stored in the inductor into the battery B2 during each switching cycle, inductor saturation should be avoided to achieve a reliable reset. As such, the duty ratio of the switch is designed to not exceed 0.5 , such that $\mathrm{D} \leq 0.5$.

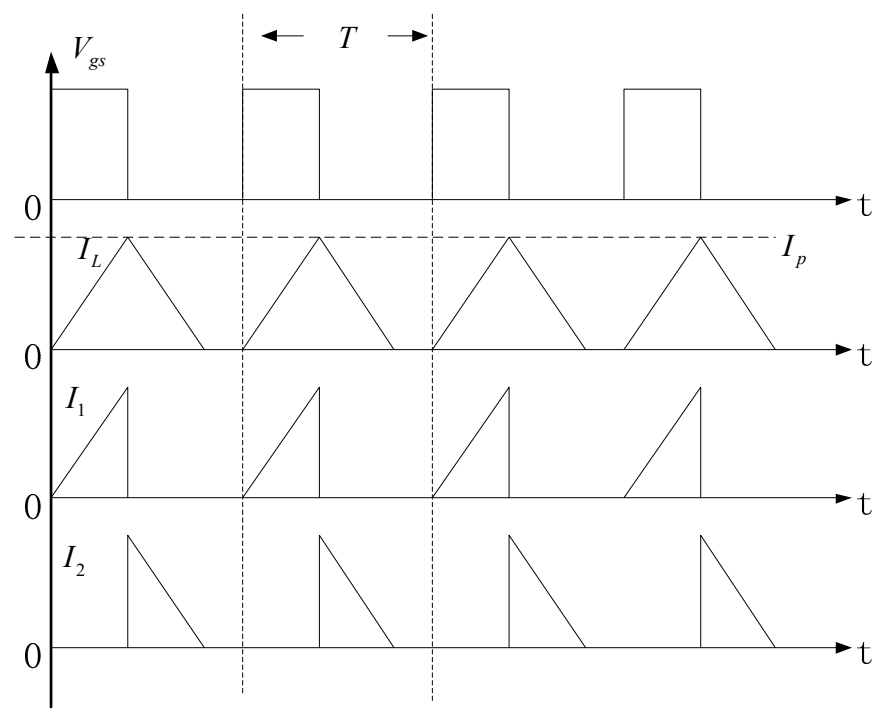

Figure 8. Current waveform. 
The frequency of the MOSFET was set to $10 \mathrm{kHz}$ in this study and the condition prompting the start of equalization is the voltage difference $\Delta \mathrm{u} \geq 0.025 \mathrm{~V}$. The maximum equalization current is $2 \mathrm{~A}$ and the nominal voltage of the lithium battery is $3.6 \mathrm{~V}$. Using Formula (13), an equalization inductor (connected between the single batteries) of $100 \mu \mathrm{H}$ was selected, while for that between the groups, an inductor of $200 \mu \mathrm{H}$ was used.

\subsection{Analysis of Simulation Results}

In order to verify the effectiveness of the proposed equilibrium topology and fast equalization strategy, this paper built a simulation model and performed simulations of static equalization, charge equalization, and discharge equalization. The equalization system was constructed as shown in Figure 9. Since this study used the terminal voltage as the equalization condition, the battery part of the simulation model was modeled as a capacitor, as was done in reference [26]. This made it easier to set different initial voltages. The value of the capacitor can be calculated in such a way that the battery capacity is equal to the quantity of electricity that is charged to the capacitor from the lower limit of the cut-off voltage to the upper limit of the cut-off voltage of the battery. $(\mathrm{C} 1=\mathrm{C} 2=\mathrm{C} 3=\mathrm{C} 4=13,000 \mathrm{~F})$. The control relied on the error in the terminal voltages of different batteries within a series, and the terminal voltages of different modules between the series, to realize closed-loop PWM output control.

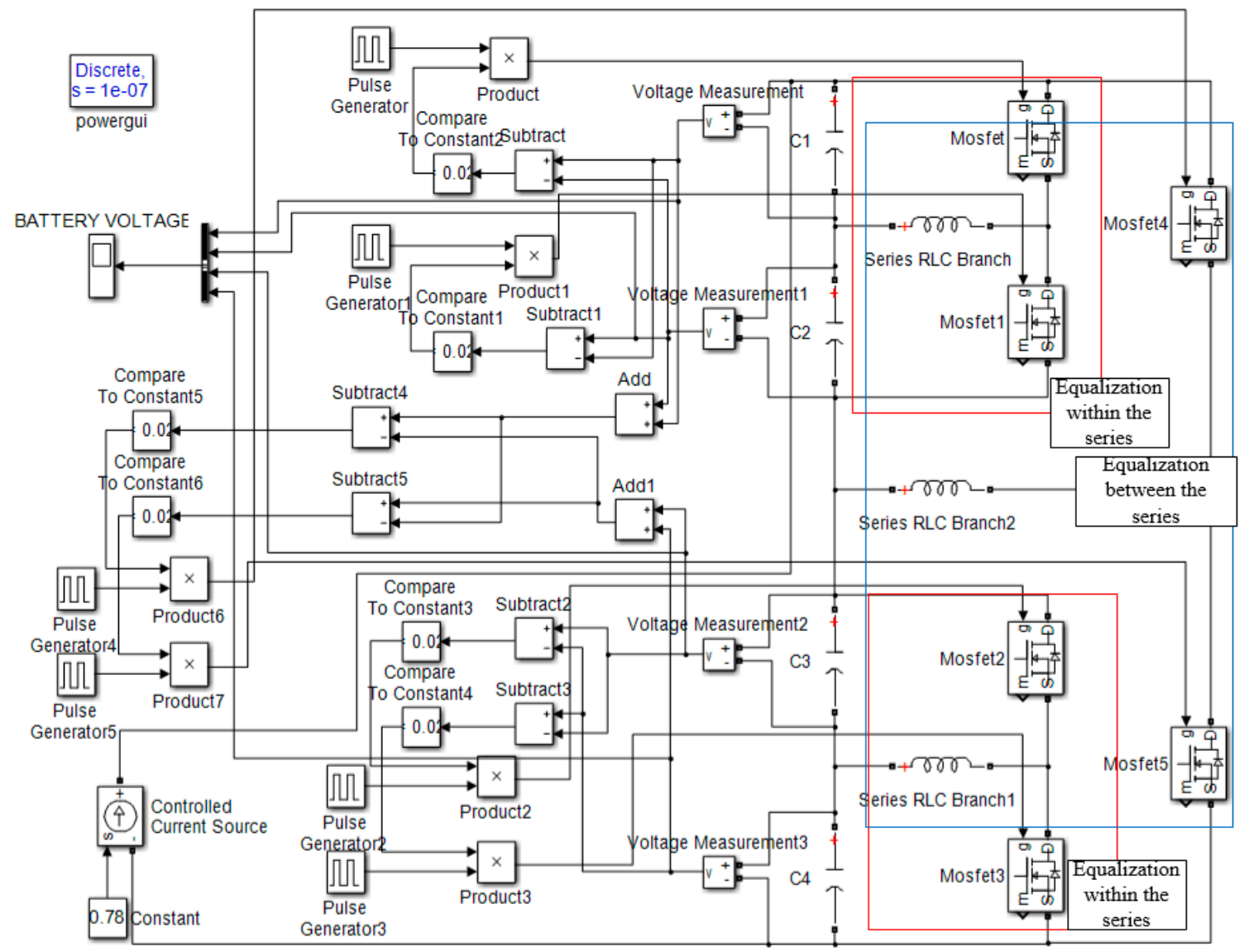

Figure 9. Active equalization circuit simulation structure.

\subsubsection{Static Equalization Simulation}

In the static equalization simulation, the initial values of B1, B2, B3, and B4 are set to $4.15 \mathrm{~V}$, $4.10 \mathrm{~V}, 3.85 \mathrm{~V}$, and $3.70 \mathrm{~V}$, respectively. The sum of the voltages of $\mathrm{B} 1$ and $\mathrm{B} 2$ is $\mathrm{C} 1$, which is $8.25 \mathrm{~V}$, and that of $\mathrm{B} 3$ and $\mathrm{B} 4$ is $\mathrm{C} 2$, which is $7.55 \mathrm{~V}$. After starting the equalization process, the condition for turning the equalization on is determined. Because $V_{\mathrm{B} 1}-V_{\mathrm{B} 2} \geq 0.025 \mathrm{~V}, V_{\mathrm{B} 3}-V_{\mathrm{B} 4} \geq 0.025 \mathrm{~V}$, and 
$\left(V_{\mathrm{C} 1}-V_{\mathrm{C} 2}\right) / 2 \geq 0.025 \mathrm{~V}$, the equalization condition is satisfied and the equalization mode is turned on. At this time, B1 transfers energy to B2, and B3 transfers energy to B4, while B1 and B2 transfer energy to B3 and B4. At time T1, B1 and B2 complete the equalization. At time T2, B3 and B4 complete the equalization. During the equalization process, the voltages of $\mathrm{B} 1$ and $\mathrm{B} 2$ gradually decrease, and the voltages of B3 and B4 gradually increase. At time T3, the four cells are in equilibrium; their voltages tend to be the same and the equalization ends, as shown in Figure 10.

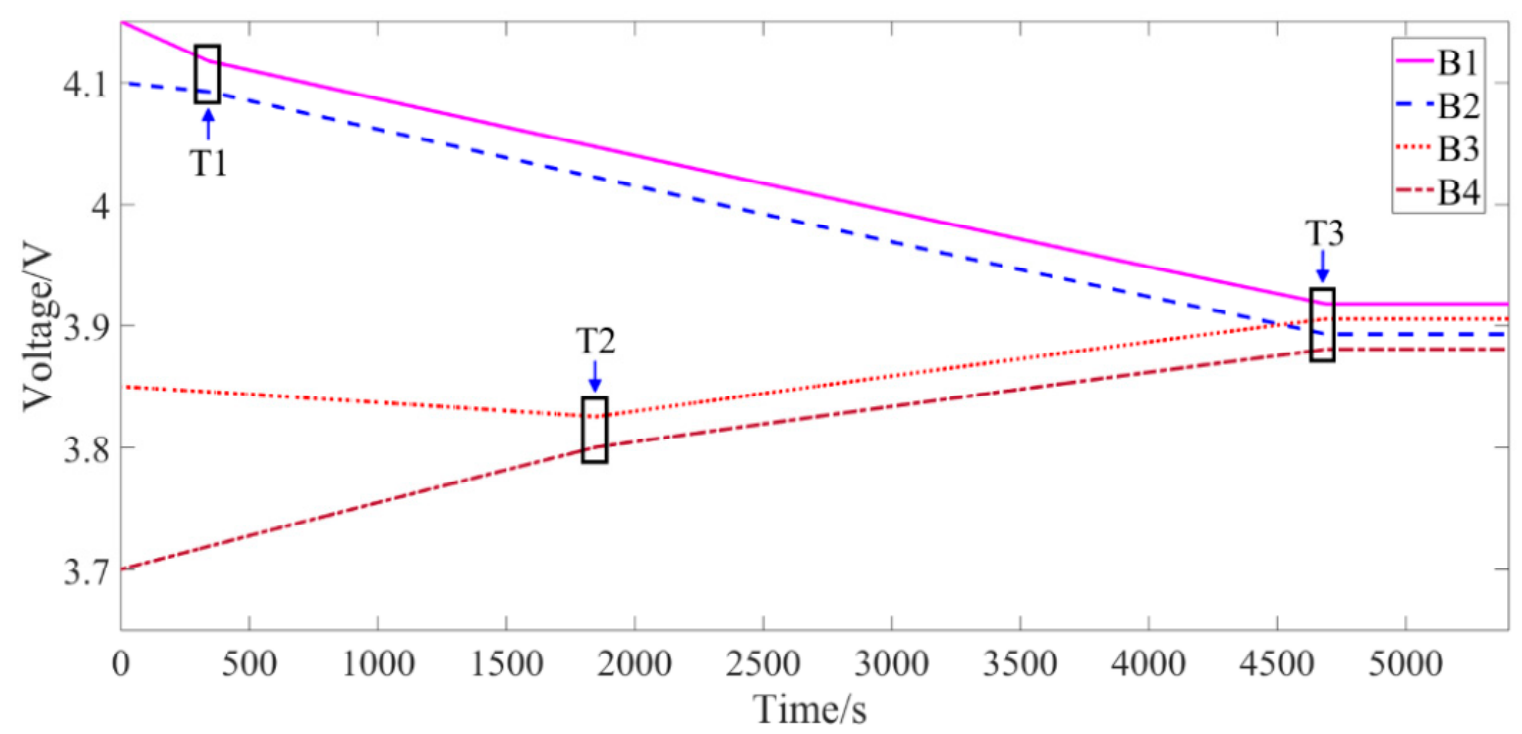

Figure 10. Static state simulation results.

It can be seen from the equilibrium simulation results that the equalization circuit can complete the equalization at approximately $4670 \mathrm{~s}$ in the static state, which proves the effectiveness of the proposed equalization circuit and control strategy in achieving a rapid balance of the battery pack under static conditions.

\subsubsection{Charge Equalization Simulation}

In the charge equalization simulation, the initial values of B1, B2, B3, and B4 are set to $3.75 \mathrm{~V}$, $3.85 \mathrm{~V}, 3.65 \mathrm{~V}$, and $3.80 \mathrm{~V}$, respectively. The sum of the voltages of $\mathrm{B} 1$ and $\mathrm{B} 2 \mathrm{is} \mathrm{C} 1$, which is $7.6 \mathrm{~V}$, and the sum of the voltages of B3 and B4 is C2, which is $7.45 \mathrm{~V}$. The charging current is set to $1.3 \mathrm{~A}$ ( $0.5 \mathrm{C}$ current rate). After starting the equalization process, first determine the condition for turning the equalization on. Because $V_{\mathrm{B} 2}-V_{\mathrm{B} 1} \geq 0.025 \mathrm{~V}, V_{\mathrm{B} 4}-V_{\mathrm{B} 3} \geq 0.025 \mathrm{~V}$, and $\left(V_{\mathrm{C} 1}-V_{\mathrm{C} 2}\right) / 2 \geq 0.025 \mathrm{~V}$, the equalization condition is satisfied and the equalization mode is turned on. At this time, B2 transfers energy to B1 and B4 transfers energy to B3, while B1 and B2 transfer energy to B3 and B4. Because the battery pack is in a charging state, B1 and B2 have a slower rate of increase in voltage during charging, whereas B3 and B4 charge faster, as shown in Figure 11. At T1, the four batteries are equalized, the voltages tend to be uniform, and the equalization ends.

From the results of the equalization simulation, it can be seen that under the state of charging, the equalization circuit can complete the equalization in approximately $1830 \mathrm{~s}$, which proves the effectiveness of the proposed equalization circuit and control strategy in achieving the rapid balance of the battery pack under charging conditions. 


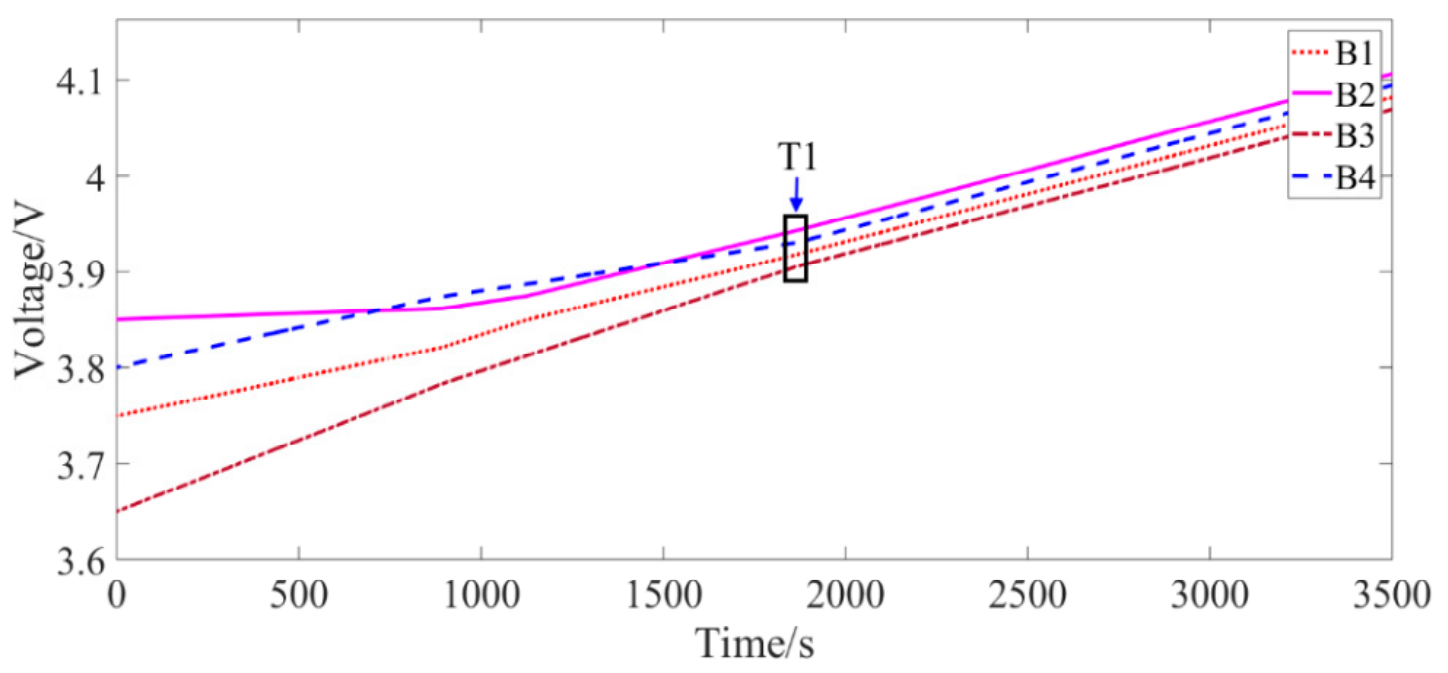

Figure 11. Charging state simulation results.

\subsubsection{Discharge Equalization Simulation}

In the discharge equalization simulation, the initial values of B1, B2, B3, and B4 are set to $4.15 \mathrm{~V}$, $4 \mathrm{~V}, 4.1 \mathrm{~V}$, and $3.85 \mathrm{~V}$, respectively. The sum of the voltages of $\mathrm{B} 1$ and $\mathrm{B} 2$ is $\mathrm{C} 1$, which is $8.15 \mathrm{~V}$, and the sum of the voltages of $\mathrm{B} 3$ and $\mathrm{B} 4$ is $\mathrm{C} 2$, which is $7.95 \mathrm{~V}$. The discharging current is set to $1.3 \mathrm{~A}$ ( $0.5 \mathrm{C}$ current rate). After the equalization is started, the condition for turning the equalization on is first determined. Because $V_{\mathrm{B} 1}-V_{\mathrm{B} 2} \geq 0.025 \mathrm{~V}, V_{\mathrm{B} 3}-V_{\mathrm{B} 4} \geq 0.025 \mathrm{~V}$, and $\left(V_{\mathrm{C} 1}-V_{\mathrm{C} 2}\right) / 2 \geq 0.025 \mathrm{~V}$, the equalization condition is satisfied and the equalization mode is turned on. At this time, B1 transfers energy to B2 and B3 transfers energy to B4, while B1 and B2 transfer energy to B3 and B4. Because the battery pack is in the discharge state, B1 and B2 have a faster rate of voltage drop during discharge, whereas B3 and B4 discharge at a slower rate, as shown in Figure 12. At T1, the four batteries are equalized; the voltages tend to be uniform and the equalization ends.

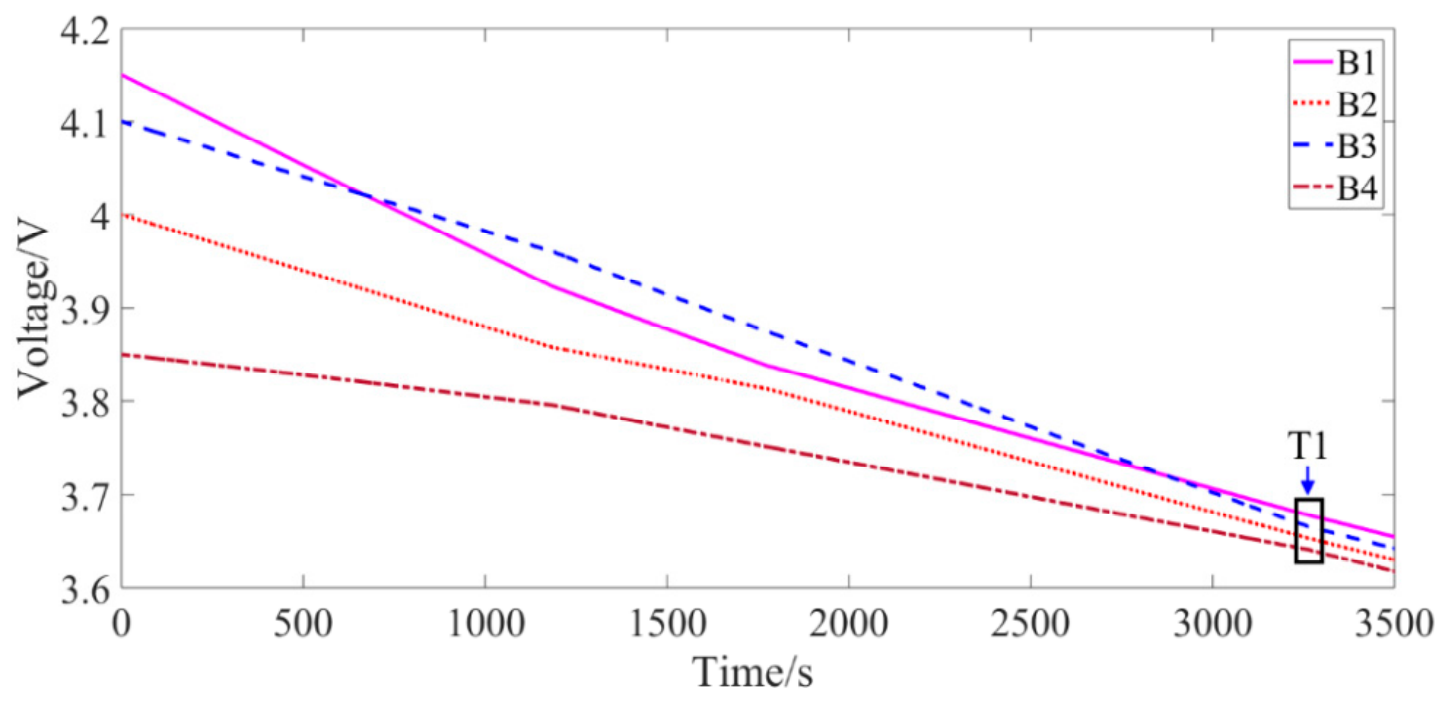

Figure 12. Discharging state simulation results.

It can be seen from the equilibrium simulation results that in the discharge state, the equalization circuit can complete the equalization at approximately $3300 \mathrm{~s}$, which proves the effectiveness of the proposed equalization circuit and control strategy to achieve rapid balancing of the battery pack under the discharging condition. 


\subsection{Analysis of Experimental Results}

To further verify the effectiveness of the proposed method, the equilibrium strategy proposed in this paper is compared with the experimental results using the equilibrium strategy mentioned in [26]. The equilibrium strategy used in [26] is based on the same equilibrium topology, but the layers in the two-layer equalization module do not operate simultaneously. Instead, the equalization module of the first layer first performs the equalization. After the battery pack is equalized, the second layer is evenly equilibrium, that is, the intra-group equalization and inter-group equalization are achieved. In order to distinguish between these two equalization strategies, the equilibrium strategy in [26] is called Equalization strategy 1. The strategy of simultaneous equalizations within and between groups proposed in this paper is called Equalization strategy 2. The flow chart of the equalization strategy in [26] is shown in Figure 13. In this paper, three sets of verification experiments, namely, battery static state equalization, battery charging state equalization, and battery discharging state equalization, were designed to verify the effectiveness of the proposed equalization strategy.

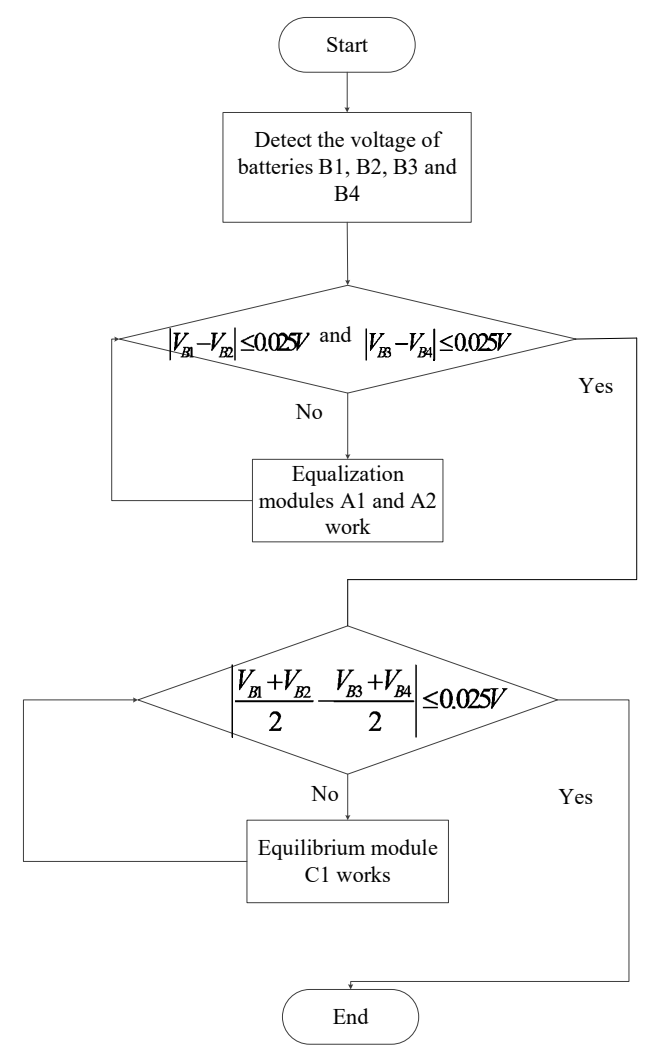

Figure 13. Flowchart for the battery pack equalization strategy in [26].

The experimental platform built in this paper is shown in Figure 14, which mainly includes a battery test system, high-precision adjustable power supply, equalization circuit, DSP development board, and CCS host computer software. In the equalization circuits, the MOSFET is an N-channel-type IRFB38N20DPbF produced by Infineon. This MOSFET has a conduction internal resistance of $54 \mathrm{~m} \Omega$ and a low energy loss. The turn-off delay is $29 \mathrm{~ns}$, and the response is fast, making it suitable for a battery equalization system. The voltage of the battery is scaled down first and then input into the A/D sampling port of the DSP, given that the DSP's A/D sampling input voltage cannot exceed $3 \mathrm{~V}$. In the voltage acquisition circuit, an OP747 produced by AD is used as the pre-stage operational amplifier, while a MCP6042 produced by Microchip is used as the post-voltage follower. The OP747 chip is an inexpensive operational amplifier with four rail-to-rail outputs, making it suitable for the measurement of the voltages of the four batteries used in this study. Further, it is suitable for the voltage sampling 
of series-connected batteries because it has a low power consumption and anti-high common mode voltage input characteristics. The voltage-sampling circuit is shown in Figure 15.

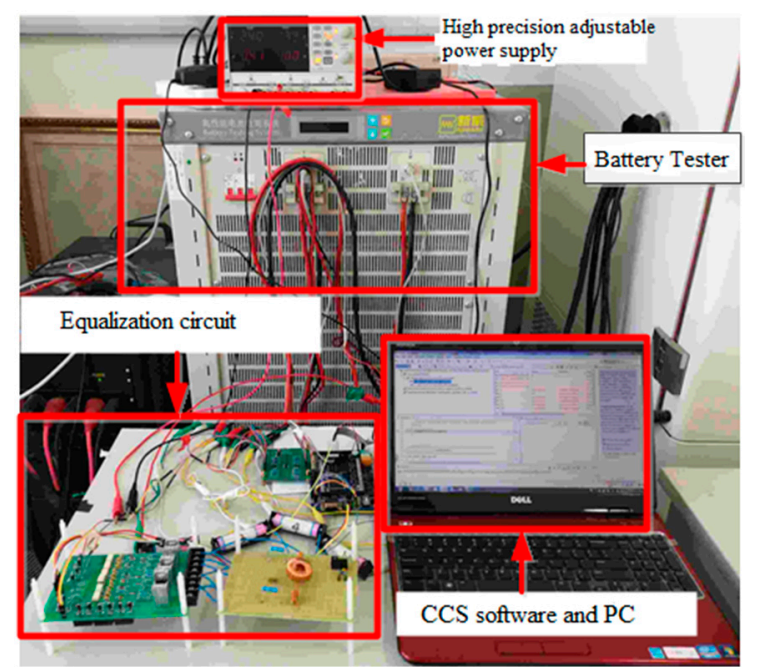

Figure 14. Active equilibrium system platform.

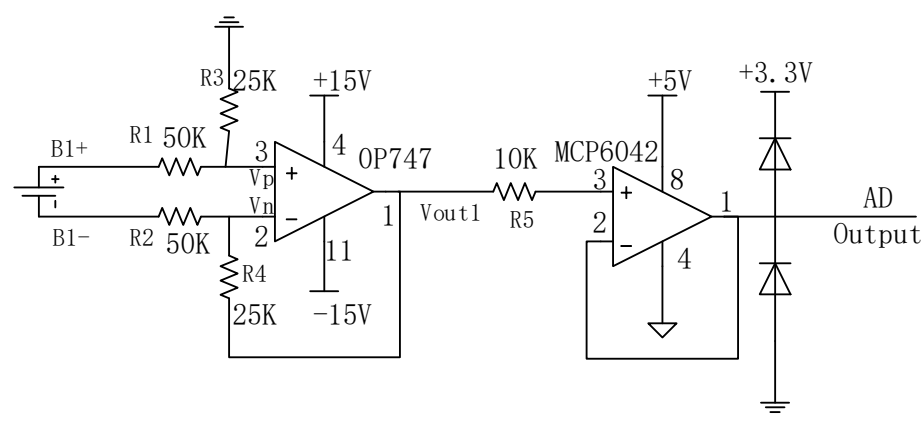

Figure 15. Voltage-sampling circuit.

The high-precision adjustable voltage source can accurately adjust the voltage output range to provide 24-V input voltage to the auxiliary power module in the circuit; the battery test system can charge and discharge the battery pack, raise fault alarm, and set the voltage and current range of the battery. It can record the battery voltages for analyzing the experimental effect of the battery equalization.

\subsubsection{Experiment on Static Equilibrium of Battery Pack}

Initially, the battery was in equilibrium in the static state. Before the experiment, the four batteries were set to different voltage values and three of the batteries were fully charged, that is, the SOC was $100 \%$; the voltage of the other battery was set to approximately $3.8 \mathrm{~V}$. Figure 16 shows the results of the battery equalization experiment.

As can be seen from Figure 16, the inconsistency in the four-cell battery voltage is significantly improved after the battery pack is equalized. In the later stage of the equalization, it can be seen that the voltage values of the respective battery cells tend to be uniform. In this paper, Equalization strategy 1 could complete the battery equalization in approximately $110 \mathrm{~min}$, whereas Equalization strategy 2 completed the equalization in $73 \mathrm{~min}$. With regard to the static equilibrium time, the speed of the equalization strategy proposed in this paper was 33.6\% higher than that of Equalization strategy 1. 


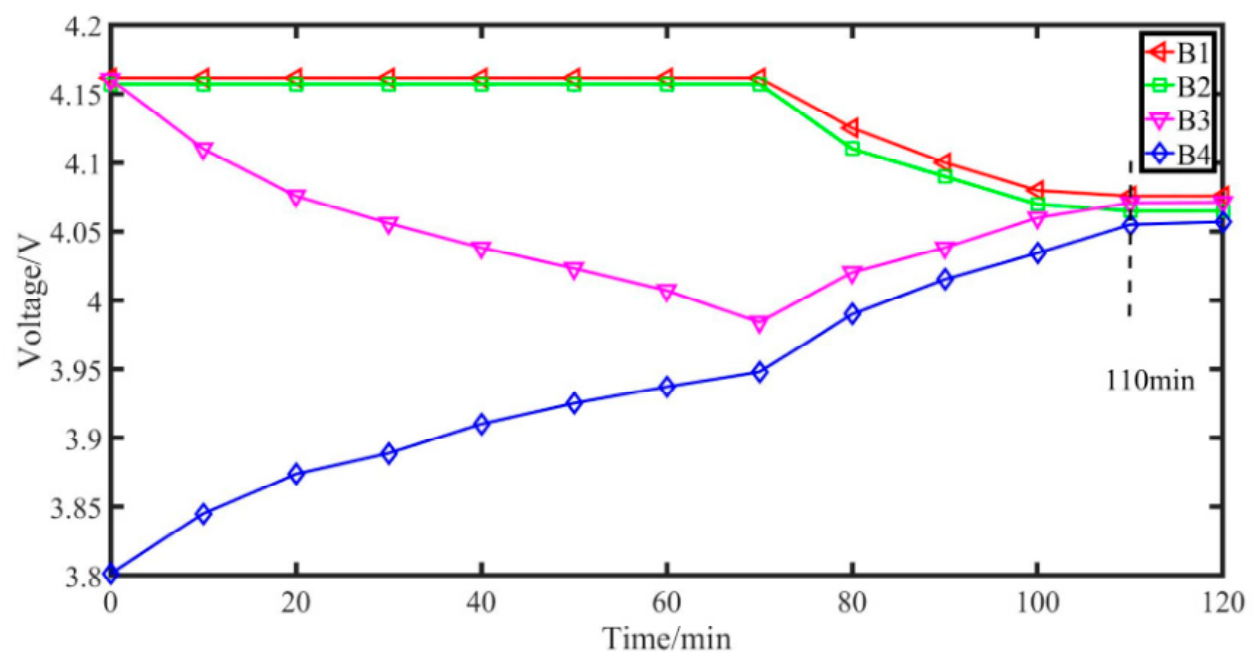

(a) Equalization strategy 1

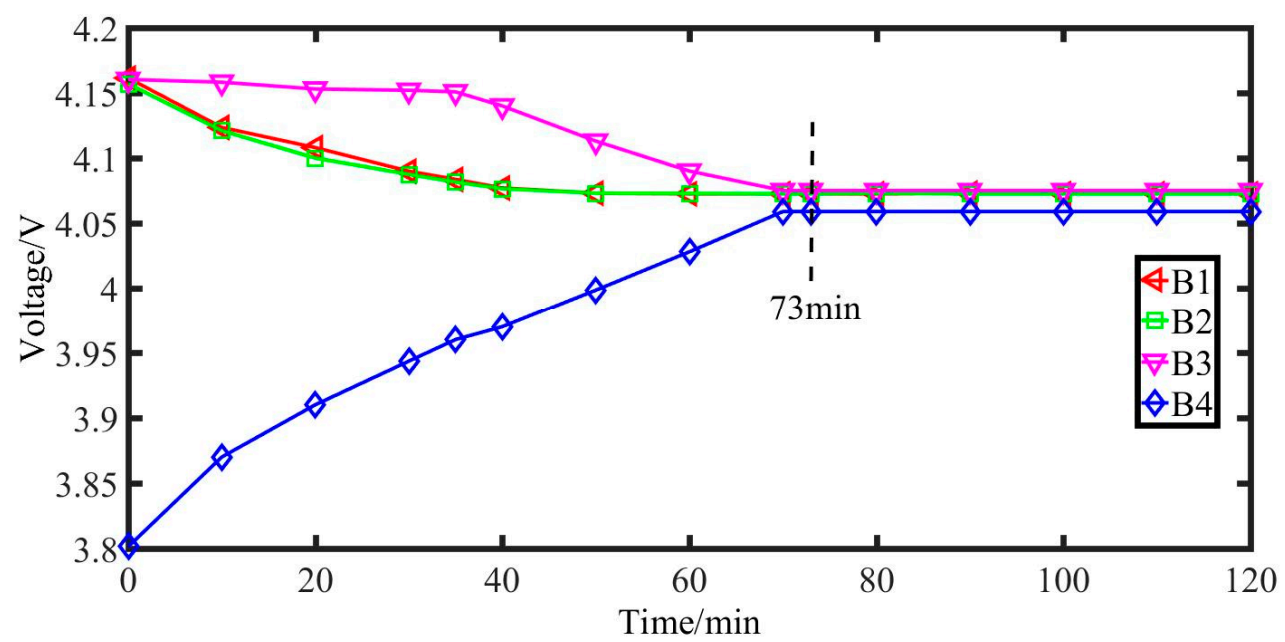

(b) Equalization strategy 2

Figure 16. Experimental results of active equalization in static state.

\subsubsection{Battery Pack Charge Equalization Experiment}

The equalization experiment for the battery in the charging state was performed. Before the experiment, the four batteries were set to different voltage values and three of the batteries were fully discharged, that is, the SOC was $0 \%$; the other battery voltage was set to approximately $3.70 \mathrm{~V}$. Figure 17 shows the results of the battery equalization experiment. 


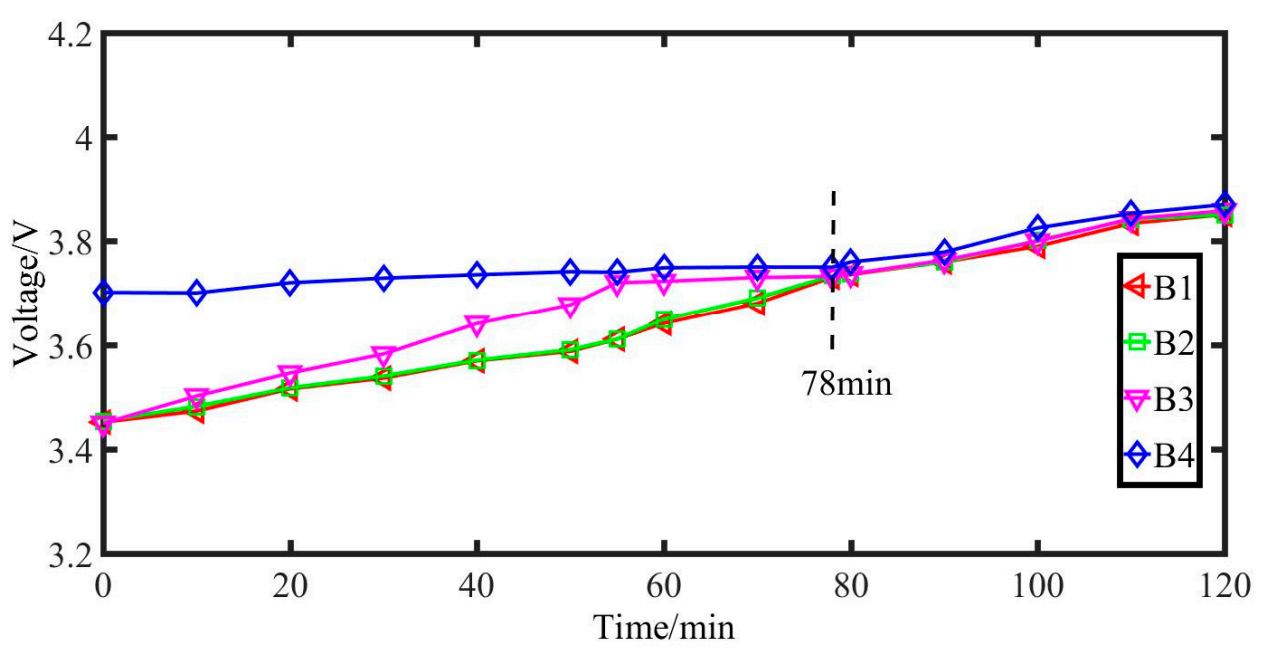

(a) Equalization strategy 1

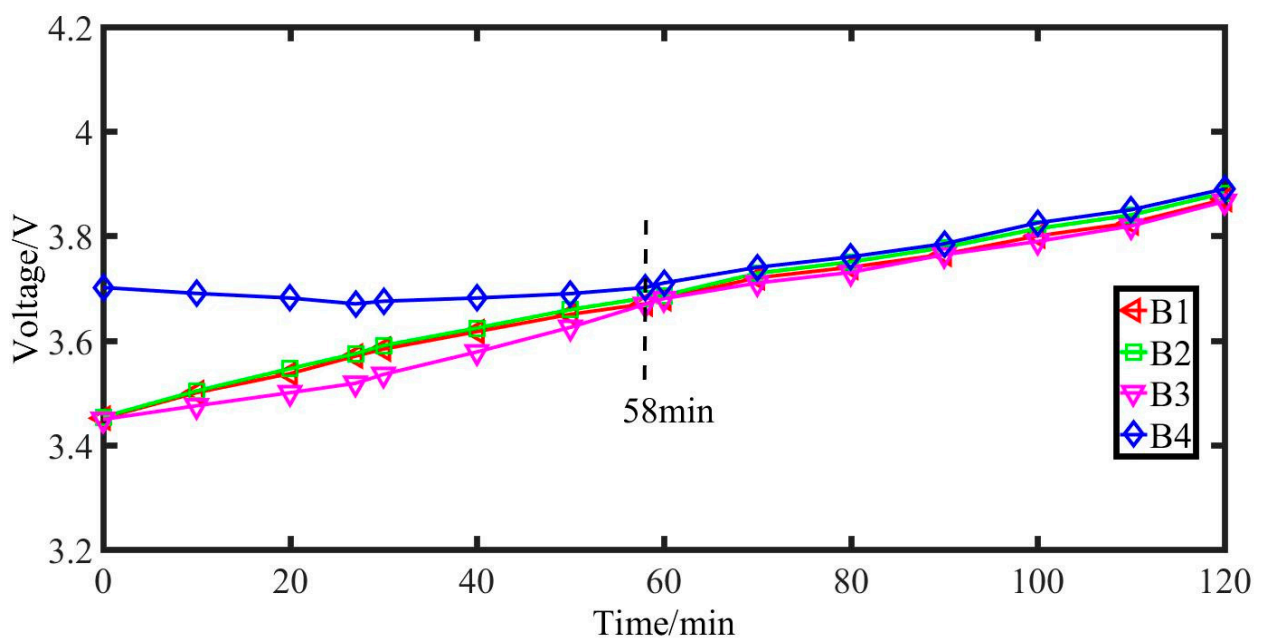

(b) Equalization strategy 2

Figure 17. Experimental results of active equalization in charging state.

It can be seen from Figure 17 that the inconsistency in the voltage of the four-cell battery is significantly improved after the battery pack is equalized. In the later stage of the equalization, it can be seen that the voltage values of the battery cells tend to be uniform. In this paper, Equalization strategy 1 could complete the battery equalization in approximately $78 \mathrm{~min}$, whereas Equalization strategy 2 could complete the equalization in $58 \mathrm{~min}$. With regard to the time required for completion of charge equalization, the speed of the equalization strategy proposed in this paper was $25.6 \%$ higher than that of Equalization strategy 1.

\subsubsection{Battery Pack Discharge Equalization Experiment}

Before the experiment, the four batteries were set to different voltage values-three of the batteries were fully charged, that is, the SOC was $100 \%$, and the other battery voltage was set to approximately $3.85 \mathrm{~V}$. Figure 18 shows the results of the battery equalization experiment. 


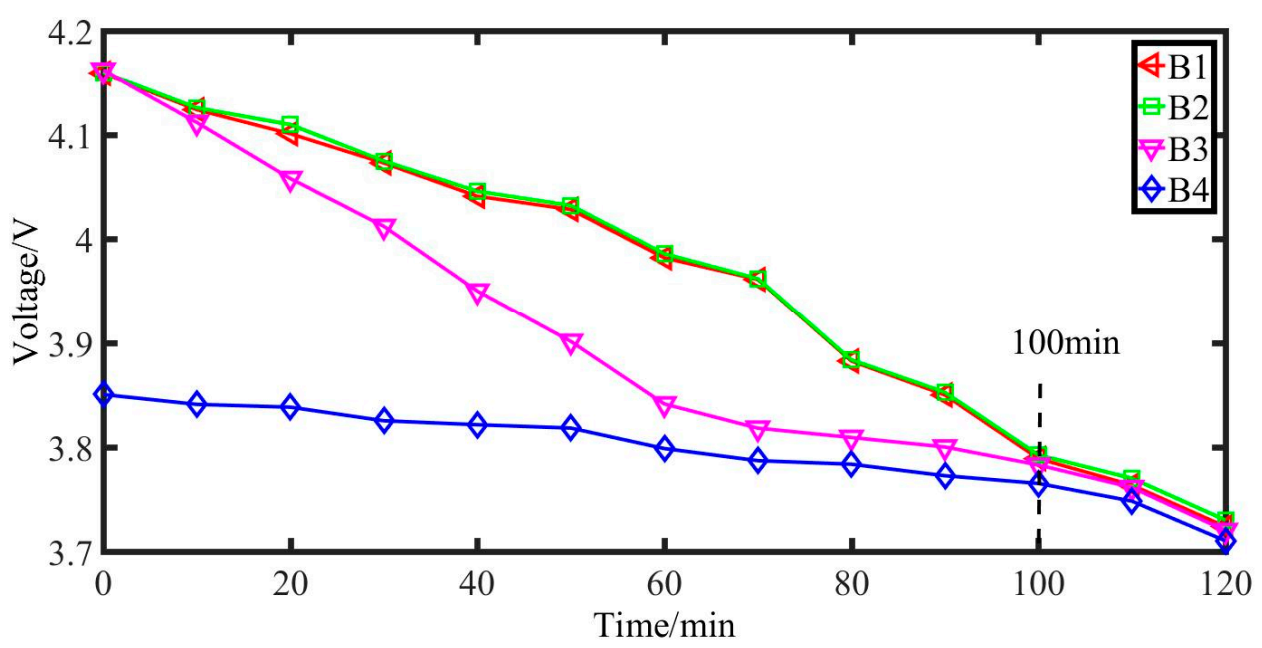

(a) Equalization strategy 1

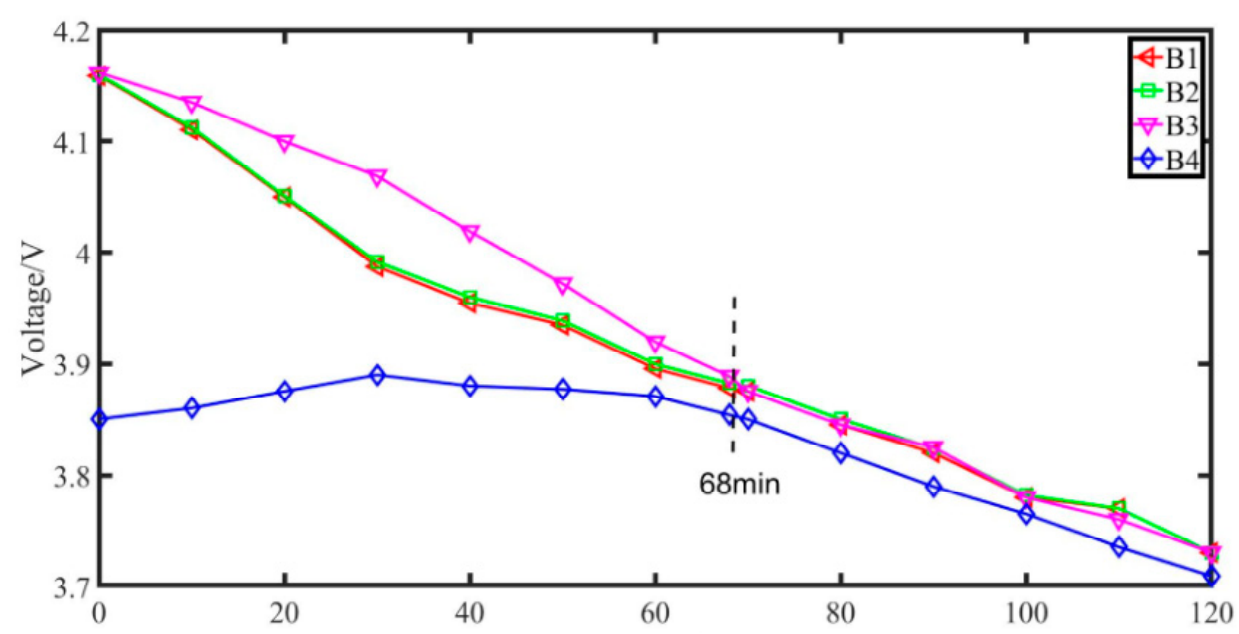

(b) Equalization strategy 2

Figure 18. Experimental results of active equalization in discharging state.

As can be seen from Figure 18, the inconsistency in the four-cell battery voltage is significantly improved after equalization of the battery pack. In the later stage of the equalization, it can be seen that the voltage values of the respective battery cells tend to be uniform. In this paper, Equalization strategy 1 completed the battery pack equalization in approximately $100 \mathrm{~min}$, whereas Equalization strategy 2 completed it in $68 \mathrm{~min}$. Thus, the equalization speed of the proposed equalization strategy was $32 \%$ higher than that of Equalization strategy 1.

\section{Conclusions}

In this paper, an active hierarchical equalization circuit topology was used in a series battery pack. Based on this, a fast control strategy for simultaneous equalizations within and between groups was proposed. Taking a four-cell battery as an example, online simulation and experimental verifications of the equalization process of the battery pack were performed in the stationary state, the charging state, and the discharging state. The simulation and experimental results showed that the designed battery equalization system could achieve fast equalization of the series battery pack in the three states. 
Compared with the equilibrium strategy that performs equalization between the first and the latter groups, the proposed equalization strategy, which achieves simultaneous equalizations within and between the packs, has obvious advantages in terms of equalization speed and equalization time.

Author Contributions: Conceptualization, X.W.; Data Curation, Y.L.; Writing-Original Draft Preparation, X.L.; Writing-Review \& Editing, Z.C.; Funding Acquisition, J.D.

Funding: This research received no external funding.

Acknowledgments: This work was sponsored through the National Natural Science Foundation of China (51877057 and 51877121); University Nursing Program for Young Scholars with Creative Talent in Heilongjiang Province (UNPYSCT-2016164); State Key Laboratory of Automotive Safety and Energy under Project No. KF1826; National Key Technologies R\&D Program of MOST of China (2018YFB0106102).

Conflicts of Interest: The authors declare no conflict of interest.

\section{References}

1. Xiong, R.; Duan, Y.; Cao, J.; Yu, Q. Battery and ultracapacitor in-the-loop approach to validate a real-time power management method for an all-climate electric vehicle. Appl. Energy 2018, 217, 153-165. [CrossRef]

2. Hu, X.; Yuan, H.; Zou, C.; Li, Z.; Zhang, L. Co-estimation of state of charge and state of health for lithium-ion batteries based on fractional-order calculus. IEEE Trans. Veh. Technol. 2018, 67, 10319-10329. [CrossRef]

3. See, K.; Lim, K.C.; Batternally, S.; Zhang, N. Charge based self-equalization for imequalization battery pack in an energy storage management system developing a time-based equalization algorithm. IEEE Consum. Electr. Mag. 2019, 8, 16-21. [CrossRef]

4. Ouyang, Q.; Chen, J.; Zheng, J.; Fang, H. Optimal multi objective charging for lithium-ion battery packs: A hierarchical control approach. IEEE Trans. Ind. Inform. 2018, 14, 4243-4253. [CrossRef]

5. Thuc, M.B.; Kim, C.H.; Kim, K.H.; Rhee, S.B. A modular cell equalization based on multi-winding transformer and switched-capacitor circuits for a series-connected battery string in electric vehicles. Appl. Sci. 2018, 8, 1278.

6. Chen, Y.; Liu, X.; Fathy, H.K.; Zou, J.; Yang, S. A graph-theoretic framework for analyzing the speeds and efficiencies of battery pack equalization circuits. Int. J. Electr. Power Energy Syst. 2018, 98, 85-99. [CrossRef]

7. Shang, Y.; Zhang, C.; Cui, N.; Mi, C.C. A delta-structured switched-capacitor equalizer for series-connected battery strings. IEEE Trans. Power Electr. 2019, 34, 452-461.

8. Shang, Y.; Cui, N.; Duan, B.; Zhang, C. Analysis and optimization of star-structured switched-capacitor equalizers for series-connected battery strings. IEEE Trans. Power Electr. 2018, 33, 9631-9646. [CrossRef]

9. Wang, X.; Cheng, K.E.; Fong, Y.C. Non-equal voltage cell balancing for battery and super-capacitor source package management system using tapped inductor techniques. Energies 2018, 11, 1037. [CrossRef]

10. Liu, X.; Wan, Z.; He, Y.; Zheng, X.; Zeng, G.; Zhang, J. A unified control strategy for inductor-based active battery equalization schemes. Energies 2018, 11, 405. [CrossRef]

11. Zhang, C.; Shang, Y.; Li, Z.; Cui, N. An interleaved equalization architecture with self-learning fuzzy logic control for series-connected battery strings. IEEE Trans. Veh. Technol. 2017, 66, 10923-10934. [CrossRef]

12. Liu, X.; Sun, Y.; He, Y. Battery Equalization by Fly-Back Transformers with Inductance, Capacitance and Diode Absorbing Circuits. Energies 2017, 10, 1482. [CrossRef]

13. Ye, Y.; Cheng, K.W.E. Analysis and Design of zero-current switching switched-capacitor cell balancing circuit for series-connected battery/supercapacitor. IEEE Trans. Veh. Technol. 2018, 67, 948-955. [CrossRef]

14. Liu, M.; Fu, M.; Wang, Y. Battery cell equalization via megahertz multiple-receiver wireless power transfer. IEEE Trans. Power Electr. 2018, 33, 4135-4144. [CrossRef]

15. Uno, M.; Kukita, A. PWM converter integrating switched capacitor converter and series-resonant voltage multiplier as equalizers for photovoltaic modules and series-connected energy storage cells for exploration rovers. IEEE Trans. Power Electr. 2017, 32, 8500-8513. [CrossRef]

16. Ouyang, Q.; Chen, J.; Zheng, J. Optimal cell-to-cell balancing topology design for serially connected Lithium-Ion battery packs. IEEE Trans. Sustain. Energy 2018, 9, 350-360. [CrossRef]

17. Wu, Z.; Ling, R.; Tang, R. Dynamic battery equalization with energy and time efficiency for electric vehicles. Energy 2017, 141, 937-948. [CrossRef] 
18. Diao, W.; Xue, N.; Bhattacharjee, V.; Jiang, J.; Karabasoglu, O.; Pecht, M. Active battery cell equalization based on residual available energy maximization. Appl. Energy 2018, 210, 690-698. [CrossRef]

19. Zhou, F.; Lv, Z. A novel charging/discharging balancing strategy for lithium battery pack based on mixed charging mode. IEEJ Trans. Electr. Electron. Eng. 2017, 12, 615-622. [CrossRef]

20. Preindl, M. A Battery balancing auxiliary power module with predictive control for electrified transportation. IEEE Trans. Ind. Electron. 2018, 65, 6552-6559. [CrossRef]

21. Ouyang, Q.; Chen, J.; Zheng, J. SOC estimation-based quasi-sliding mode control for cell balancing in Lithium-Ion battery packs. IEEE Trans. Ind. Electron. 2018, 65, 3427-3436. [CrossRef]

22. Zheng, J.; Chen, J.; Ouyang, Q. Variable universe fuzzy control for battery equalization. J. Syst. Sci. Complex. 2018, 31, 325-342. [CrossRef]

23. Qi, J.; Lu, D. A Preventive approach for solving battery imequalization issue by using a bidirectional multiple-input cuk converter working in DCVM. IEEE Trans. Ind. Electron. 2017, 64, 7780-7789. [CrossRef]

24. Zheng, X.; Liu, X.; He, Y. Active vehicle battery balancing scheme in the condition of constant-voltage/current charging and discharging. IEEE Trans. Veh. Technol. 2017, 66, 3714-3723. [CrossRef]

25. Wang, S.; Kang, L.; Guo, X.; Wang, Z.; Liu, M. A novel layered bidirectional equalizer based on a buck-boost converter for series-connected battery strings. Energies 2017, 10, 1011. [CrossRef]

26. Lü, H.; Liu, C.; Yin, D. The design and optimize of equalization schemes for underwater power $\mathrm{LiFePO}_{4}$ battery stack. Trans. China Electrotech. Soc. 2016, 31, 232-239.

(C) 2019 by the authors. Licensee MDPI, Basel, Switzerland. This article is an open access article distributed under the terms and conditions of the Creative Commons Attribution (CC BY) license (http://creativecommons.org/licenses/by/4.0/). 